\title{
ASSISTÊNCIA DE AR EM BARRA DE PULVERIZAÇÃO NO CONTROLE DA FERRUGEM ASIÁTICA DA SOJA ( $\left.{ }^{1}\right)$
}

\author{
RAFAEL DE SOUZA CHRISTOVAM $\left({ }^{2,3}\right)$; CARLOS GILBERTO RAETANO $\left({ }^{2 *}\right)$; \\ HÉLIO OLIVEIRA AGUIAR JUNIOR $\left({ }^{2}\right)$; MARIO HENRIQUE FERREIRA DO AMARAL \\ DAL-POGETTO $\left({ }^{2,3}\right)$; EVANDRO PEREIRA PRADO $\left({ }^{2,3}\right)$; MARCELO JUNIOR GIMENES $\left({ }^{2,3}\right)$; \\ VILSON LUÍS KUNZ $\left.{ }^{2}\right)$
}

\begin{abstract}
RESUMO
O experimento foi instalado em Botucatu, na cultura da soja, safra 2006/2007. Duas tecnologias de aplicação foram comparadas: pulverização convencional (sem ar); pulverização com assistência de ar na barra nas velocidades de 9, 11 e $29 \mathrm{~km} \mathrm{~h}^{-1}$, sobre alvos artificiais, no controle da ferrugem asiática, em diferentes partes das plantas. Para a superfície adaxial das folhas, na parte superior das plantas, a assistência de ar com $11 \mathrm{~km} \mathrm{~h}^{-1}$, proporcionou maiores depósitos na superfície das folhas. Na parte inferior das plantas não houve diferença significativa entre os tratamentos. Quanto aos depósitos na superfície abaxial das folhas, na parte superior da planta, a velocidade de ar máxima gerada pelo ventilador $\left(29 \mathrm{~km} \mathrm{~h} \mathrm{~h}^{-1}\right.$, proporcionou maiores níveis de depósitos. A assistência de ar proporcionou maior produtividade da soja, diferindo da pulverização convencional (sem ar) e testemunha (plantas não tratadas).
\end{abstract}

Palavras-chave: tecnologia de aplicação, deposição, controle químico.

\section{ABSTRACT \\ AIR-ASSISTANCE IN SLEEVE BOOM SPRAY IN THE CONTROL OF SOYBEAN RUST}

The experiment was set in Botucatu, São Paulo State, Brazil, in the soybean crop, harvest 2006/07. Two application technologies have been compared: conventional spraying (without air); spraying with air assistance in the sleeve boom at 9, 11 and $29 \mathrm{~km} \mathrm{~h}^{-1}$ of the air speed on artificial targets as well as in the control of soybean rust in different parts of the plants. For the adaxial surface of leaves in the top part of the plants, the air assistance with $11 \mathrm{~km} \mathrm{~h}^{-1}$, provided greaters spray deposits. In the bottom part of the plants it was not observed significative differences between the treatments. The deposits in the abaxial surface of leaves in the top part of the plant, with maximum air speed generated by the fan (29 $\mathrm{km} \mathrm{h}^{-1}$ ), provided greaters levels of deposits. The air assistance provided a higher productivity, in relation to conventional spraying (without air) and check (no treated).

Key words: application technology, deposition, chemical control.

$\left({ }^{1}\right)$ Parte da dissertação de mestrado do primeiro autor. Recebido para publicação em 13 de novembro de 2008 e aceito em 15 de outubro de 2009.

$\left({ }^{2}\right)$ Departamento de Produção Vegetal, Faculdade de Ciências Agronômicas - UNESP, Caixa Postal 237, 18603-970 Botucatu (SP), Brasil. E-mail: srchristovam@bol.com.br; raetano@fca.unesp.br (*) Autor correspondente.

$\left({ }^{3}\right)$ Bolsista CNPq. 


\section{INTRODUÇÃO}

Atualmente, um dos fatores que acarreta o aumento do custo de produção da cultura da soja é, sem dúvida, a aplicação de produtos fitossanitários. Atualmente, a doença mais preocupante na cultura é a ferrugem asiática, causada pelo fungo Phakopsora pachyrhizi H. Sydow \& Sydow, que, se não controlada, pode provocar a perda total da cultura (YORINORI et al., 2004).

Nos últimos anos, a ferrugem asiática tem merecido atenção especial devido à sua severidade $\mathrm{e}$ dificuldade de controle, por se desenvolver em toda a parte aérea da planta prejudicando sua fisiologia e reduzindo drasticamente a produção de grãos.

No Brasil, lavouras livres da doença ferrugem asiática da soja, podem alcançar uma produtividade média de 55 sacas ha $^{-1}$, com custo de produção por volta de 40,6 sacas ha $^{-1}$, sendo recomendável o controle do agente causal da doença (YORINORI, 2005).

Para o controle eficiente da ferrugem e a redução dos custos de produção deve-se aprimorar as técnicas e os equipamentos de aplicação de produtos fitossanitários, visando melhorar a distribuição da pulverização e a colocação do produto no alvo desejado, mais especificamente nas folhas localizadas no baixeiro da cultura, onde a doença inicia sua infestação.

Uma das técnicas utilizadas para melhorar a eficiência dos produtos fitossanítários no combate à ferrugem asiática da soja é a utilização de tamanho de gotas que proporcionam boa cobertura, variando entre 200 e $300 \mu \mathrm{m}$ (OZKAN, 2005). No entanto, podem ser utilizadas gotas menores que $100 \mu \mathrm{m}$, com controle de deriva, e pulverizadores dotados de assistência de ar na barra de pulverização.

Estudos evidenciam que o uso da assistência de ar junto à barra de pulverização, reduz a deriva, aumentando a penetração das gotas no dossel da cultura e melhorando a distribuição da pulverização (TAYlOR et al., 1989; COOKE et al., 1990; TAYLOR e Andersen, 1991; Bauer e Raetano, 2000; Raetano e BAUER, 2003).

Para a definição das estratégias de controle da ferrugem, quanto à tecnologia de aplicação, deve-se conhecer como os fungicidas sistêmicos se movimentam nas plantas após a aplicação e absorção. No mercado atual, a maioria dos fungicidas indicados para o controle da ferrugem da soja causam movimento no sentido da base para o ápice de cada folha, com mínima chance de movimentação no sentido contrário e sem a possibilidade de translocação de uma folha para outra (ANTUNIASSI, 2005).
Para os produtos de contato ou de menor ação sistêmica, o uso de gotas menores e/ou maior volume de calda torna-se necessário, devido à maior dependência com relação à cobertura dos alvos. Os produtos sistêmicos podem ser aplicados com menor densidade de gotas, permitindo o uso de gotas maiores, o que facilita a adoção de técnicas para redução de deriva e melhora a segurança da aplicação aumentando a eficiência. Se usadas de maneira correta, gotas grossas proporcionam bom nível de depósito, mas não proporcionam boas condições de cobertura e penetração (ANTUNIASSI, 2006).

No Brasil, novas técnicas de aplicação de produtos fitossanitários, têm sido desenvolvidas na Região Centro-Oeste (Cerrado) para controle da ferrugem asiática. Assim, o presente trabalho teve como objetivo comparar diferentes tecnologias de aplicação de produtos fitossanitários: barra de pulverização com e sem assistência de ar, sobre alvos artificiais, bem como o efeito dessas tecnologias no controle da ferrugem asiática, sobre parâmetros da produção e produtividade da cultura da soja.

\section{MATERIAL E MÉTODOS}

O experimento foi instalado em Botucatu, Gleba Cascalheira, na cultura da soja, com a cv. Conquista, na safra agrícol de 2006/2007. A área está situada a uma altitude de 724 metros, a $22^{\circ} 48^{\prime} 59,7^{\prime \prime}$ $\mathrm{S}$ e $48^{\circ} 25^{\prime} 38,2^{\prime \prime} \mathrm{W}$.

A seleção da cultivar Conquista deveu-se à arquitetura da planta com folhas maiores, ciclo de desenvolvimento mais prolongado e porte da planta maior, características que proporcionam um microclima favorável ao desenvolvimento da ferrugem asiática da soja.

A semeadura da soja foi realizada em 18/12/ 2006, com espaçamento de $0,45 \mathrm{~m}$ entre linhas de plantio, no sistema de plantio convencional. A colheita foi realizada em 4/5/2007.

Utilizou-se o delineamento de blocos ao acaso, com quatro tratamentos: 0, 9, 11 e $29 \mathrm{~km} \mathrm{~h}^{-1}$ de velocidade do ar na barra de pulverização, em seis repetições, totalizando 24 unidades experimentais, com dimensões de 8,0 x 10,0 m (largura $x$ comprimento). Para o controle da ferrugem asiática, empregaram-se os mesmos tratamentos, acrescido da testemunha (plantas não tratadas), com seis repetições, totalizando 30 unidades experimentais.

A regulagem da velocidade do ar junto à barra foi feita pelo número de voltas do dispositivo controlador da rotação do ventilador: zero, sem a presença de ar, e a partir do número máximo de voltas 
dada no controlador (sentido horário aumenta a velocidade e anti-horário diminui a velocidade do ar), proporcionando a velocidade de ar máxima $29 \mathrm{~km} \mathrm{~h}^{-1}$, medida a 0,50 m da saída do ar na barra. Em seguida, foram estabelecidas as velocidades de ar de 9 e $11 \mathrm{~km} \mathrm{~h}^{-1}$ com $50 \%$ e $75 \%$ respectivamente, a partir do número máximo de voltas do dispositivo controlador da velocidade do ar, pois a relação entre rotação do ventilador e velocidade de ar gerado não é linear. A velocidade do ar na barra do pulverizador tracionado modelo Advance vortex 2000 foi medida com auxílio de um anemômetro digital.

Para avaliação dos depósitos, foi utilizado

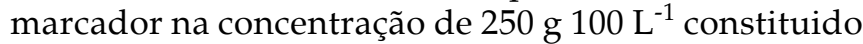
de um produto cúprico (Cobox) na forma de oxicloreto de cobre, com equivalência de $50 \%$ de cobre metálico, visando à quantificação do volume de calda depositado em alvo artificial.

O pulverizador foi equipado com pontas de pulverização de jato plano XR 8002, operando à pressão de 251,50 kPa para a aplicação de $125 \mathrm{~L} \mathrm{ha}^{-1}$. A velocidade de deslocamento do conjunto tratorpulverizador foi $7 \mathrm{~km} \mathrm{~h}^{-1}$ e a altura da barra foi de 0,50 m acima do dossel da cultura. Três aplicações foram realizadas na cultura, duas no estádio de desenvolvimento R2 (85 dias após semeadura), sendo uma delas para avaliação dos depósitos e outra visando ao controle do patógeno. Já no estádio de desenvolvimento R 5.2 (100 dias após semeadura) uma terceira aplicação foi feita visando ao controle da ferrugem asiática da soja. Durante a primeira pulverização, as condições meteorológicas foram as seguintes: umidade relativa do ar entre $62 \%$ e $64,1 \%$, temperatura variando de 28 a $29^{\circ} \mathrm{C}$ e velocidade do vento entre 3,9 e $7,9 \mathrm{~km} \mathrm{~h}^{-1}$, no período de $16 \mathrm{~h} 45 \mathrm{~min}$ a $17 \mathrm{~h} 40 \mathrm{~min}$. Nesse momento, a cultura estava no estádio de desenvolvimento R2. Já para as pulverizações, visando ao controle da ferrugem asiática, com a mistura fungicida azoxistrobina + ciproconazole, as condições climáticas foram as seguintes: R2 (umidade relativa do ar entre $69 \%$ e $70 \%$, temperatura entre 27,8 e $28,2^{\circ} \mathrm{C}$ e velocidade do vento entre 8,6 e $10,3 \mathrm{~km} \mathrm{~h}^{-1}$, no período de $9 \mathrm{~h} 50 \mathrm{~min}$ a $11 \mathrm{~h} 15 \mathrm{~min}$ ) e R 5.2 (umidade relativa do ar entre $72,2 \%$ e $74,1 \%$, temperatura entre 27,5 e $28,3{ }^{\circ} \mathrm{C}$ e velocidade do vento entre 4,1 e $8,2 \mathrm{~km} \mathrm{~h}^{-1}$, no período de $15 \mathrm{~h} 40 \mathrm{~min}$ a $16 \mathrm{~h} 30 \mathrm{~min}$ ).

\section{Alvo artificial}

Nas avaliações dos depósitos da aplicação optou-se pelo uso de alvo artificial pela necessidade de quantificá-los nas superfícies abaxial e adaxial dos folíolos. Em alvo natural, a remoção dos depósitos seria por lavagem, o que dificultaria a obtenção de resultados individualizados dos depósitos nas respectivas superfícies foliares.

Partindo dessa premissa, foi utilizado como alvo papel-filtro com dimensão de 0,03 x 0,03 m, distribuídos em 10 plantas, sob a barra de pulverização no sentido perpendicular ao deslocamento do equipamento. Em cada uma das plantas foram fixados quatro alvos coletores, um na superfície adaxial e outro na superfície abaxial de um mesmo folíolo, nas partes superior e inferior da planta.

Para a avaliação das perdas da aplicação, foram colocadas em cada tratamento três placas de Petri de 8,5 cm de diâmetro, com papel filtro a 0,10 m de altura do solo, posicionadas no carreador, dentro e fora do dossel da cultura. O posicionamento das placas a $0,10 \mathrm{~m}$ de altura da superfície do solo possibilitou a obtenção de amostras nas placas livres de partículas do solo quando ocorreu o acionamento da assistência de ar na barra de pulverização.

\section{Extração e quantificação do marcador}

Após a execução do tratamento, foi retirada uma amostra da calda de pulverização. Os alvos artificiais foram coletados das folhas e colocados em vidros contendo $20 \mathrm{~mL}$ de solução extratora de ácido nítrico a $1,0 \mathrm{~mol} \mathrm{~L}^{-1}$ e, após 15 minutos de agitação em velocidade de $220 \mathrm{rpm}$, seguida por 24 horas de descanso, as soluções de lavagem foram levadas ao espectrofotômetro de absorção atômica, modelo AA6300 SHIMADZU para quantificação do íon cobre $(\mathrm{Cu})$, conforme método utilizado por CHAIm et al., (1999). As placas de Petri distribuídas dentro e fora da cultura foram também lavadas com a mesma quantidade da solução extratora e o mesmo procedimento foi realizado para a quantificação do marcador.

\section{Monitoramento de Phakopsora pachyrhizi}

Após o início do estádio de desenvolvimento reprodutivo ( $R$ ), foram realizadas avaliações semanais do número de pústulas por unidade de área $\left(\mathrm{cm}^{-2}\right)$ em folíolos retirados da parte inferior da planta. Duas amostras de folhas (trifólios) foram retiradas de cada parcela, as quais em seguida, colocadas em sacos plásticos transparentes, para facilitar a diagnose da doença. Em seguida, os sacos foram amarrados e as amostras, levadas para quantificação do número de pústulas por $\mathrm{cm}^{2}$. $\mathrm{O}$ corte no folíolo da secção correspondente à área de $1 \mathrm{~cm}^{2}$ foi realizado na superfície abaxial e ao lado da nervura central; a contagem das pústulas na área seccionada foi realizada sob microscópio estereoscópio. 


\section{Avaliação dos parâmetros de produção e produtividade}

Para avaliação do efeito da assistência de ar no controle da ferrugem asiática sobre a produção da soja foi realizada a colheita dentro de cada parcela, sendo colhidas três linhas de plantio centrais com tamanho de $8 \mathrm{~m}$ de comprimento, com auxílio de uma colhedora de parcelas experimentais da Marca Wintersteiger, modelo seedmech. Foram avaliados os seguintes parâmetros da produção: massa de 1000 sementes e classificação por tamanho de peneiras $(17,16,15,14$ e 13) e fundo (grãos de tamanho inferior aos das demais peneiras). Também foi avaliada a produtividade $\left(\mathrm{kg} \mathrm{ha}^{-1}\right)$ da cultura nos diferentes tratamentos, com umidade das sementes corrigida a $13 \%$.

\section{Análise estatística}

Os dados dos depósitos do marcador, expressos em $\mu \mathrm{L} \mathrm{cm}^{-2}$, foram analisados separadamente para as superfícies abaxial e adaxial nas diferentes partes da planta (superior e inferior). A severidade da doença, as perdas dos depósitos, bem como os parâmetros de produção e produtividade foram submetidos à analise de variância e as médias comparadas pelo teste de Tukey a $5 \%$ de probabilidade.

\section{RESULTADOS E DISCUSSÃO}

\section{Depósitos da pulverização}

Os valores médios dos depósitos da aplicação expressos pelo volume de calda $\left(\mu \mathrm{L} \mathrm{cm}^{-2}\right)$ capturado em diferentes posições da planta, estão relacionados na tabela 1.
Verifica-se que não houve influência da velocidade do ar em diferentes posições da planta sobre os depósitos da pulverização. Para a superfície adaxial das folhas na parte superior das plantas, a assistência de ar com $11 \mathrm{~km} \mathrm{~h}^{-1}$ da velocidade de ar gerado pelo ventilador, foi a que obteve maior depósito na superficie das folhas; para a parte inferior da superfície adaxial não houve diferença significativa entre os tratamentos. Quanto aos depósitos na superficie abaxial das folhas, nas partes superior e inferior da planta, a velocidade de ar máxima gerada pelo ventilador $\left(29 \mathrm{~km} \mathrm{~h}^{-1}\right)$ proporcionou maiores depósitos na superfície das folhas. Os maiores níveis dos depósitos na superfície abaxial dos folíolos com a maior velocidade do ar pode estar relacionado à maior deflexão do ar pela superfície do solo, porém são muitas as dificuldades para o estudo da dinâmica das gotas de pulverização associadas à assistência de ar em condições de campo. RAETANO e BAuER (2003), também constataram melhores níveis dos depósitos da pulverização na superfície abaxial dos foliolos inferiores do feijoeiro com a utilização da assistência de ar, operada a plena capacidade do ventilador.

Quando se comparam os depósitos do marcador na superfície abaxial dos folíolos, nas diferentes partes da planta, verificam-se níveis significativamente maiores na parte superior, exceto para a velocidade de $29 \mathrm{~km} \mathrm{~h}^{-1}$, o que pode ser explicado pela interceptação das gotas pelas folhas nessa parte da planta (Tabela 1). Ao avaliar o efeito da assistência de ar em cultura de soja, no estádio de desenvolvimento R6, BAUER e RAETANO (2000) também constataram aumento na deposição da pulverização quando foi utilizada a assistência de ar na barra pulverizadora.

Tabela 1. Depósitos da pulverização do marcador cúprico, em alvo artificial (papel-filtro) nas superfícies dos folíolos, das partes superior e inferior das plantas de soja, cultivar Conquista. Botucatu (SP), 2006/2007

\begin{tabular}{|c|c|c|c|c|}
\hline \multirow{3}{*}{ Velocidade do Ar } & \multicolumn{4}{|c|}{ Depósitos de pulverização } \\
\hline & \multicolumn{2}{|c|}{ Adaxial } & \multicolumn{2}{|c|}{ Abaxial } \\
\hline & Superior & Inferior & Superior & Inferior \\
\hline \multicolumn{5}{|l|}{$\mathrm{km} \mathrm{h}^{-1}$} \\
\hline 0 & 2,9920 a $A B$ & $1,2237 \mathrm{~b} \mathrm{~A}$ & 1,1617 a $B$ & $0,6042 \mathrm{~b} \mathrm{~A}$ \\
\hline 9 & 2,6764 a B & $0,9838 \mathrm{~b} \mathrm{~A}$ & 1,0612 a B & $0,4106 \mathrm{~b} \mathrm{~A}$ \\
\hline 11 & 3,9989 a A & $1,0199 \mathrm{~b} \mathrm{~A}$ & 1,0460 a B & $0,3866 \mathrm{~b}$ A \\
\hline 29 & 2,6234 a B & $0,9596 \mathrm{~b} \mathrm{~A}$ & 1,7227 a $\mathrm{A}$ & $0,6247 \mathrm{~b}$ A \\
\hline DMS (Velocidade Ar) & \multicolumn{2}{|c|}{1,0147} & \multicolumn{2}{|c|}{0,4014} \\
\hline DMS (Posição planta) & \multicolumn{2}{|c|}{0,764} & \multicolumn{2}{|c|}{0,2137} \\
\hline CV (\%) & \multicolumn{2}{|c|}{31,63} & \multicolumn{2}{|c|}{41,55} \\
\hline
\end{tabular}

Médias seguidas de mesma letra, minúscula na linha e maiúscula na coluna, não diferem estatisticamente entre sí, pelo teste de Tukey (p $\leq$ 0,05). 


\section{Avaliação das perdas da pulverização}

Não houve interação significativa entre velocidades do ar sobre as perdas dos depósitos na cultura (interior do dossel e carreador) ou fora dela (a 1,0 m da extremidade da barra) (Tabela 2).

Maiores volumes de calda foram detectados nos alvos posicionados no carreador, pois não havia obstáculos à deposição das gotas nesses alvos. Depósitos significativamente menores foram obtidos no interior do dossel e "fora" da cultura pela interceptação das gotas nas folhas, independentemente da velocidade do ar junto à barra de pulverização. Também não se constatou efeito da velocidade do ar sobre os depósitos nos diferentes locais de posicionamento dos alvos artificiais (placa de Petri).

\section{Severidade da ferrugem asiática da soja}

Os valores médios do número de pústulas por área $\left(\mathrm{cm}^{2}\right)$ obtidos antes e após as aplicações R 2 (85
DAS) e R 5.2 (100 DAS) da mistura fungicida azoxistrobina + ciproconazole na dosagem de $200+$ 80 g i.a $L^{-1}$ para o controle de $P$. pachyrhizi estão listados na tabela 3. Somente após a segunda pulverização da mistura fungicida (100 DAS) podese constatar redução significativa do número de pústulas por $\mathrm{cm}^{2}$ nas parcelas tratadas quando comparadas à testemunha (Tabela 3).

Aos 88 e 93 DAS, a não-existência de diferença significativa entre plantas tratadas com a mistura fungicida e aquelas não tratadas, quanto ao número médio de pústulas, provavelmente deveu-se a elevada porcentagem de infestação do patógeno aos 80 DAS (Figura 1), aliado à suscetibilidade à doença nesse estádio de desenvolvimento da planta.

Não se observou efeito de variação na velocidade do ar sobre a severidade da doença, pois aos 80 DAS o nível de severidade já estava acima de $5 \%$. Portanto, a combinação assistência de ar e fungicida resultou em menores níveis de severidade aos 100 DAS (Figura 1) quando comparados as plantas não tratadas.

Tabela 2. Volume de calda capturado por placa de Petri $\left(\mu \mathrm{L} c \hat{I}^{2}\right)$ em diferentes posições e velocidades de ar na cultura da soja, cultivar Conquista. Botucatu (SP), 2006/2007

\begin{tabular}{lcccc}
\hline Posição coletor $\left({ }^{1}\right)$ & \multicolumn{3}{c}{ Velocidade de ar } \\
\cline { 2 - 5 } & 0 & 9 & 11 & 29 \\
\cline { 2 - 5 } Fora & 0,0519 a B & 0,0631 a B & 0,0668 a B & 0,0593 a B \\
Dentro & 0,8011 a B & 0,5378 a B & 0,3820 a B & 1,0719 a B \\
Carreador & 5,4299 ab A & 4,9181 b A & 4,7845 b A & 6,2607 a A \\
\hline
\end{tabular}

$\mathrm{CV}(\%)=48,5$

DMS Posição coletor $=1,02$

DMS Velocidade de ar $=1,29$

$\left.{ }^{1}\right)$ Em relação à cultura da soja.

Médias seguidas de mesma letra, minúscula na linha e maiúscula na coluna, não diferem estatisticamente entre si, pelo teste de Tukey ( $\mathrm{p} \leq 0,05)$.

Tabela 3. Número de pústulas de Phakopsora pachyrhizi por $\mathrm{cm}^{2}$, antes e após as aplicações da mistura fungicida azoxistrobina + ciproconazole na cultura da soja. Botucatu (SP), 2006/2007

\begin{tabular}{|c|c|c|c|c|c|c|c|}
\hline \multirow{2}{*}{ Velocidade do ar } & \multicolumn{7}{|c|}{ Dias Após Semeadura (DAS) } \\
\hline & 78 & 80 & 88 & 93 & 102 & 106 & 114 \\
\hline \multicolumn{8}{|l|}{$\mathrm{km} \mathrm{h}^{-1}$} \\
\hline 0 & $0,92 \mathrm{a}$ & $4,50 \mathrm{a}$ & $6,00 \mathrm{a}$ & $5,33 \mathrm{a}$ & $30,42 \mathrm{~b}$ & $11,75 \mathrm{~b}$ & $6,92 \mathrm{~b}$ \\
\hline 9 & $1,42 \mathrm{a}$ & $5,75 \mathrm{a}$ & $6,67 \mathrm{a}$ & $3,37 \mathrm{a}$ & $27,08 \mathrm{~b}$ & $6,92 \mathrm{~b}$ & $4,17 \mathrm{~b}$ \\
\hline 11 & $1,08 \mathrm{a}$ & $10,92 \mathrm{a}$ & 8,17 a & $6,25 \mathrm{a}$ & $18,75 \mathrm{~b}$ & $6,42 \mathrm{~b}$ & $6,50 \mathrm{~b}$ \\
\hline 29 & $1,50 \mathrm{a}$ & 9,33 a & 8,08 a & 6,67 a & $30,83 \mathrm{~b}$ & $7,83 \mathrm{~b}$ & $2,67 \mathrm{~b}$ \\
\hline Testemunha & $2,08 \mathrm{a}$ & $8,92 \mathrm{a}$ & $9,00 \mathrm{a}$ & $8,92 \mathrm{a}$ & $53,50 \mathrm{a}$ & 40,67 a & $20,00 \mathrm{a}$ \\
\hline DMS & 2,40 & 6,88 & 9,21 & 6,58 & 15,44 & 12,11 & 5,78 \\
\hline CV (\%) & 99,30 & 50,50 & 70,40 & 62,40 & 27,80 & 47,70 & 41,60 \\
\hline
\end{tabular}

Médias seguidas pela mesma letra, na coluna, não diferem estatisticamente pelo teste de Tukey $(\mathrm{p} \leq 0,05)$. 


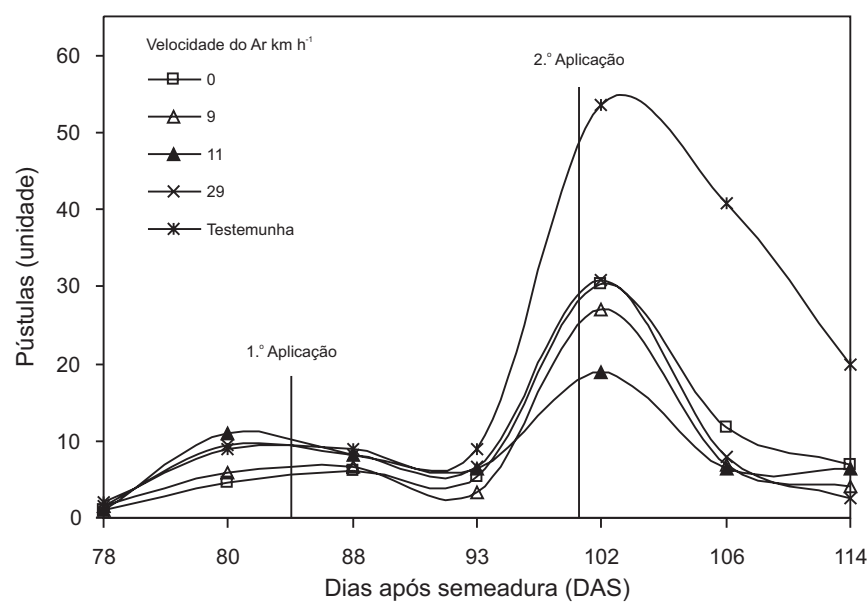

Figura 1. Severidade da ferrugem asiática da soja, antes e após duas pulverizações (R2 e R5.2), respectivamente aos 85 e 100 DAS, da mistura fungicida azoxistrobina + ciproconazole para o controle de P. pachyrhizi. Botucatu (SP), 2006/2007. Cada símbolo representa a média de seis repetições.

\section{Avaliação dos parâmetros de produção e produtividade}

A porcentagem de grãos retidos na peneira 16 foi maior que a retenção de grãos nas demais peneiras, mas não diferiu significativamente entre as velocidades de ar gerado pelo ventilador, quando se utilizou a assistência de ar na barra de pulverização (Tabela 4).

A classificação do tamanho de grãos por peneiras, tem como importância separar as sementes com o mesmo padrão em relação ao seu tamanho, a fim de alcançar populações de plantas uniformes no campo. Resultados positivos, indicativos de qualidade fisiológica superior de sementes de maior tamanho sobre as menores, em soja, foram obtidos por SMITH e CAMPER (1970), FeHR e Probst (1971), Fontes e Ohlrogge (1972) Costa et al. (1973) e SANTOS (2005).

Tabela 4. Classificação do tamanho de grãos de soja conforme a peneira, após duas pulverizações (R2 e R5.2) da mistura fungicida azoxistrobina + ciproconazole, com diferentes velocidades de ar junto à barra de pulverização para o controle de P. pachyrhizi. Botucatu (SP), 2006/2007

\begin{tabular}{|c|c|c|c|c|c|c|}
\hline \multirow{2}{*}{ Velocidade do ar } & \multicolumn{6}{|c|}{ Peneiras } \\
\hline & 17 & 16 & 15 & 14 & 13 & Fundo \\
\hline & \multicolumn{6}{|c|}{ Proporção de grãos } \\
\hline $\mathrm{km} \mathrm{h}^{-1}$ & & & 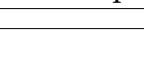 & & & \\
\hline 0 & $17,32 \mathrm{bc}$ & $33,36 \mathrm{a}$ & $31,28 \mathrm{ab}$ & $11,86 \mathrm{a}$ & $4,19 \mathrm{ab}$ & $2,44 \mathrm{a}$ \\
\hline 9 & $23,75 \mathrm{ab}$ & $35,96 \mathrm{a}$ & $25,14 \mathrm{bc}$ & 8,37 a & $3,38 \mathrm{ab}$ & $2,57 \mathrm{a}$ \\
\hline 11 & $27,00 \mathrm{a}$ & 33,67 a & $23,13 \mathrm{c}$ & 7,49 a & $3,78 \mathrm{ab}$ & $3,19 \mathrm{a}$ \\
\hline 29 & $23,78 \mathrm{ab}$ & 37,03 a & $25,17 \mathrm{bc}$ & $7,02 \mathrm{a}$ & $2,77 \mathrm{~b}$ & $2,12 \mathrm{a}$ \\
\hline Testemunha & $13,39 \mathrm{c}$ & 31,99 a & $33,43 \mathrm{a}$ & $11,78 \mathrm{a}$ & $4,62 \mathrm{a}$ & $2,59 \mathrm{a}$ \\
\hline DMS & 9,42 & 5,24 & 7,36 & 4,91 & 1,53 & 1,83 \\
\hline $\mathrm{CV}(\%)$ & 25,9 & 8,8 & 15,4 & 30,6 & 23,6 & 40,9 \\
\hline
\end{tabular}

Médias seguidas pela mesma letra, na coluna, não diferem estatisticamente pelo teste de Tukey (p $\leq 0,05)$.

Segundo Singh et al. (1972), o tamanho da semente de soja não afeta a germinação em laboratório ou em condições de campo, muito embora tenham registrado que aquelas de maior tamanho produzem plantas com massa maior de matéria seca.

De acordo com Carleton e CoOper (1972), citado por Carvalho e NaKagawa (2000), o tamanho da semente parece influir principalmente sobre a massa da plântula resultante, sendo razoável que assim seja, uma vez que as sementes grandes são aquelas que dispõem de maior quantidade de substâncias de reserva para o desenvolvimento do eixo embrionário. As sementes vigorosas proporcionam maior transferência de matéria seca de seus tecidos de reserva para o eixo embrionário, na fase de germinação, originando plântulas com maior massa, em função do maior acúmulo de matéria (NAKAgaWA, 1999).

Os valores da massa de mil sementes e da produtividade $\left(\mathrm{kg} \mathrm{ha}^{-1}\right)$ são mostrados na tabela 5. A assistência de ar não influenciou significativamente na massa de mil sementes para as plantas tratadas com a mistura fungicida azoxistrobina + ciproconazole. Provavelmente, esse fato se deve ao maior tamanho das sementes na parte superior da planta obtido no tratamento convencional (sem ar).

$\mathrm{O}$ fato de ocorrer maior penetração das gotas no interior do dossel da cultura pode ter contribuido para o melhor controle da doença, o que influenciou 
significativamente no aumento do potencial de produtividade da cultura (Tabela 5). No entanto, variações na velocidade do ar não influenciaram significativamente os parâmetros de produção e produtividade avaliados nessa pesquisa.

Tabela 5. Produção (massa de mil sementes) e produtividade da cultura da soja após duas pulverizações (R2 e R5.2) da mistura fungicida azoxistrobina + ciproconazole, com diferentes níveis de assistência de ar para o controle de $P$. pachyrhizi. Botucatu (SP), 2006/2007

\begin{tabular}{lcc}
\hline Velocidade do ar & Massa 1000 sementes & Produtividade \\
\hline $\mathrm{km} \mathrm{h}^{-1}$ & $\mathrm{~g}$ & $\mathrm{~kg} \mathrm{ha}^{-1}$ \\
0 & $139,66 \mathrm{ab}$ & $1726,53 \mathrm{~b}$ \\
9 & $145,34 \mathrm{a}$ & $2098,75 \mathrm{a}$ \\
11 & $147,28 \mathrm{a}$ & $2252,23 \mathrm{a}$ \\
29 & $146,19 \mathrm{a}$ & $2278,18 \mathrm{a}$ \\
Testemunha & $132,49 \mathrm{~b}$ & $1619,50 \mathrm{~b}$ \\
DMS & 9,81 & 338,92 \\
\hline CV (\%) & 4,00 & 9,84 \\
\hline
\end{tabular}

Médias seguidas de mesma letra, na coluna, não diferem estatisticamente pelo teste de Tukey $(\mathrm{p} \leq 0,05)$.

\section{CONCLUSÕES}

1. A assistência de ar promove aumento dos depósitos da pulverização na cultura da soja, cultivar Conquista, na superfície abaxial dos folíolos na parte superior da planta;

2. Não há influência da velocidade do ar na barra sobre as perdas nas pulverizações e na severidade da ferrugem asiática da soja;

3. A assistência de ar melhora o potencial de produtividade da cultura da soja em relação à pulverização convencional e às plantas não tratadas.

\section{AGRADECIMENTOS}

Ao Conselho Nacional de Desenvolvimento Científico e Tecnológico - CNPq, pela concessão de bolsa de estudo a Rafael de Souza Christovam.

\section{REFERÊNCIAS}

ANTUNIASSI, U.R. Tecnologia de aplicação para o controle da ferrugem da soja. In: WORKSHOP BRASILEIRO SOBRE A FERRUGEM ASIÁTICA, 1., 2005, Uberlândia. Coletânea... Uberlândia: EDUFU, 2005. p.193-219.
ANTUNIASSI, U.R. Tecnologia de aplicação de defensivos na cultura da soja. In: SUZUKI, S., YUYAMA, M.M., CAMACHO, S.A. Boletim Técnico de Pesquisa Soja 2006. Rondonópolis, MT: Fundação Mato Grosso, 2006.

BAUER, F.C.; RAETANO, C.G. assistência de ar e perdas na deposição de produtos fitossanitarios em pulverizações na cultura da soja. Scientia Agricola, v.57, p.271-276, 2000.

CARLETON, A.E.; COOPER, C.V. Seed size effects upon seedling vigor of three forage legumes. Crop Science, v.12, p.183-186, 1972.

CARVALHO, N.M; NAKAGAWA, J. Sementes: ciência, tecnologia e produção. 4. ed. Jaboticabal: FUNEP, 2000. 588p.

CHAIM, A.; VALARINI, P.J.; OLIVEIRA, D.A.; MORSOLETO, R.V.; PIO, L.C. Avaliação de perdas de pulverização em cultura de feijão e tomate. Jaguariúna: Embrapa Meio Ambiente, 1999. 29p. (Boletim de Pesquisa)

COOKE, B.K. et al. Air-assisted spraying of arable crops, in relation to deposition, drift and presticides performance. Crop Protection, v.9, p.697, 1990.

COSTA, A.V.; FONTES, L.A.N.; GALVÃO, J.D. Efeito da profundidade de plantio e do tamanho de sementes sobre a emergência e sobre algumas características agronômicas de soja. Experimentiae, v.16, p.151-172, 1973.

FEHR, W.R.; PROBST, A.H. Effect of seed source on soybean strain performance for two sucessive generations. Crop Science, v.11, p.865-867, 1971.

FONTES, L.A.W.; OHLROGGE, A.J. Influence of seed size and population on yield and other characteristics of soybean (Glycine max L.O Merrill. Agronomy Journal. v.64, p. 833-836, 1972.

NAKAGAWA. Testes de vigor baseados no desempenho das plântulas. In: KRZYZANOWSKI, F.C.; VIEIRA, R.D.; FRANÇA NETO. J.B. (Eds.). Vigor de sementes: conceitos e testes. Londrina: Abrates, 1999. cap.2, p.2.1-2.24.

OZKAN, E. Best spraying strategies to fight against Soybean Rust. 2005. Disponível em: http://www.jacto.com/ soybean_rust.html. Acesso em: 9/2006.

RAETANO, C.G.; BAUER, F.C. Efeito da velocidade do ar em barra de pulverização na deposição de produtos fitossanitários em feijoeiro. Bragantia, v.62, p.329-334, 2003.

SANTOS, P.M. Efeito da classificação por tamanho da semente de soja na sua qualidade fisiológica durante o armazenamento. Acta Scientiarum Agronomy, v.27, p. 395-402, 2005.

SINGH, J.N.; TRIPATHI, S.K.; NEGI, P.S. Note on the effect of seed size on germination, grow and yield for soybean (Glycine $\max$ L.) Merrill. Indian Journal of Agricultural Sciences, v.42, p.83-86, 1972.

SMITH, J.J.; CAMPER, H.M. Effect of seed size on soybean performance. Agronomy Abstracts, v.67, 1970. 
TAYLOR, W.A.; ANDERSEN, P.G.; COOPER, S. The use of air assistance in a field crop sprayer to reduce drift and modify drop trajectories. In: BRIGHTON CROP PROTECTION CONFERENCE-WEEDS, 3., 1989, Brighton. Proceedings... Farnham: British Crop Protection Council, 1989. p.631.

TAYLOR, W.A.; ANDERSEN, P.G. Enhancing conventional hydraulic nozzle use with the Twin Spray System. British Crop Protection Council Monograph, v.46, p.125-136, 1991.

YORINORI, J.T; JÚNIOR, J.N.; LAZZAROTTO, J.J. Ferrugem "asiática" da soja no Brasil: evolução, importância econômica e controle. Londrina: EMBRAPA Soja, 2004. 36p. (documentos, 247)

YORINORI, J.T. A ferrugem asiática da soja no continente americano: evolução, impotância econômica e estratégias de controle. In: WORKSHOP BRASILEIRO SOBRE A FERRUGEM ASIÁTICA, 1., 2005, Uberlândia. Coletânea... Uberlândia: EDUFU, 2005. p.21-37. 